\title{
Brief
}

\section{Successful use of one dose of recombinant factor VIla to control severe bleeding after emergency aortic arch replacement in deep hypothermic circulatory arrest}

Christoph Wiesenack, MD, ${ }^{a}$ Matthias Arlt, MD, ${ }^{a}$ Andreas Liebold, MD, ${ }^{\mathrm{b}}$ and Franz X. Schmid, MD, Regensburg, Germany

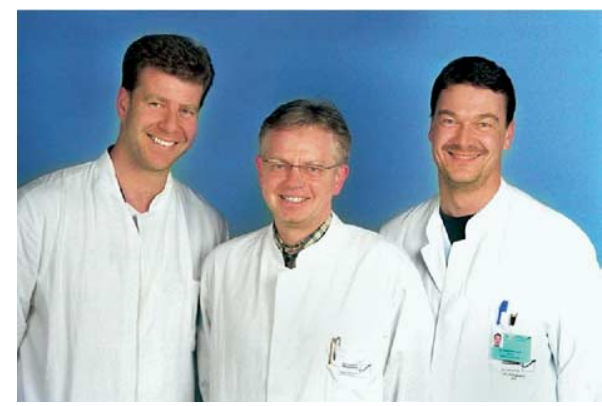

From the Departments of Anesthesiology ${ }^{\mathrm{a}}$ and Cardiothoracic and Vascular Surgery, ${ }^{\mathrm{b}}$ University Hospital of Regensburg, Regensburg, Germany.

Received for publication March 2, 2004: revisions requested March 12, 2004; revisions received March 15, 2004; accepted for publication March 18, 2004

Address for reprints: Christoph Wiesenack, MD, Department of Anesthesia, University Hospital, Franz-Josef-Strauss Allee 11, 93052 Regensburg, Germany (E-mail: christoph.wiesenack@klinik.uni-regensburg. de).

J Thorac Cardiovasc Surg 2004;128:941-3 $0022-5223 / \$ 30.00$

Copyright (C) 2004 by The American Association for Thoracic Surgery

doi:10.1016/j.jtcvs.2004.03.018

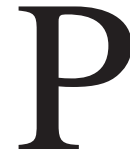

ostoperative bleeding is a common complication after prolonged cardiopulmonary bypass (CPB) with deep hypothermic circulatory arrest (DHCA). ${ }^{1}$ Experience in the off-label use of recombinant factor VIIa (rFVIIa) after cardiac surgery under the condition of DHCA is very limited, but a recent report demonstrated its efficacy in a case of life-threatening bleeding after elective aortic arch repair in a patient without preexisting hemorrhagic diathesis. ${ }^{2}$ We report a case of successfully using $\mathrm{rFVIIa}$ in the treatment of severe intractable bleeding after emergency ascending and arch replacement for acute type A aortic dissection with prolonged CPB and DHCA in a patient who received antiplatelet drugs.

\section{Clinical Summary}

A 57-year-old man was admitted to another hospital for investigation into back pain and a short episode of unconsciousness. Echocardiogram showed ST-segment elevation in the posterior and inferior leads, and the patient received heparin 10,000 IU and aspirin $500 \mathrm{mg}$ (acetylsalicylic acid) for presumed myocardial infarction. Transesophageal echocardiography, however, demonstrated a type A aortic dissection associated with a severe aortic valve insufficiency, and the patient was intubated and referred to our center for surgical treatment.

On admission, the patient's hemodynamic situation was stable under vasoactive support with norepinephrine $\left(0.05 \mu \mathrm{g} \cdot \mathrm{kg}^{-1} \cdot \mathrm{min}^{-1}\right)$. Initial coagulation parameters were normal: international normalized ratio, 1.2; activated partial thromboplastin time, 37 seconds; and platelet count, $212 \times 10^{9} / \mathrm{L}$. Chest computed tomographic findings confirmed the diagnosis and showed a dissection that reached from the aortic valve to the femoral arteries. During investigation, the patient's hemodynamic state deteriorated, and he was taken to the operating room without coronary angiography.

Anesthesia was maintained with $1.5 \%$ sevoflurane, supplemented with bolus doses of fentanyl up to $10 \mu \mathrm{g} / \mathrm{kg}$ and pancuronium $50 \mu \mathrm{g} / \mathrm{kg}$. Aprotinin $2 \times 10^{6} \mathrm{kallikrein-inhibitory}$ units (KIU) was administered before $\mathrm{CPB}$ was instituted, and another $2 \times 10^{6} \mathrm{KIU}$ were added to the CPB priming fluid, followed by a continuous infusion of $5 \times 10^{6} \mathrm{KIU} / \mathrm{h}$ for 6 hours. Activated clotting time was maintained at longer than 400 seconds during CPB, with an initial heparin dose of $375 \mathrm{IU} / \mathrm{kg}$ and an 3 additional $5000 \mathrm{IU}$ of heparin during bypass. $\mathrm{CPB}$ was instituted by right subclavian artery and right atrial cannulation. After crossclamping of the ascending aorta, cardioplegic arrest was induced by selective coronary perfusion by using Bretschneider crystalloid solution. The patient was cooled to $20^{\circ} \mathrm{C}$ tympanic temperature, and extracorporeal circulation was stopped. After aortic arch incision, antegrade cerebral perfusion was maintained by direct cannulation of the epiaortic vessels. Surgical repair included distal end-to-end anastomosis of a $26 \times 10$-mm coated Dacron (DuPont, Wilmington, Del) prothesis (Hemabridge; Intervascular, La Ciotat, France) to the descending aorta and reinsertion of a patch of native aortic tissue bearing all arch vessels to the prothesis. 


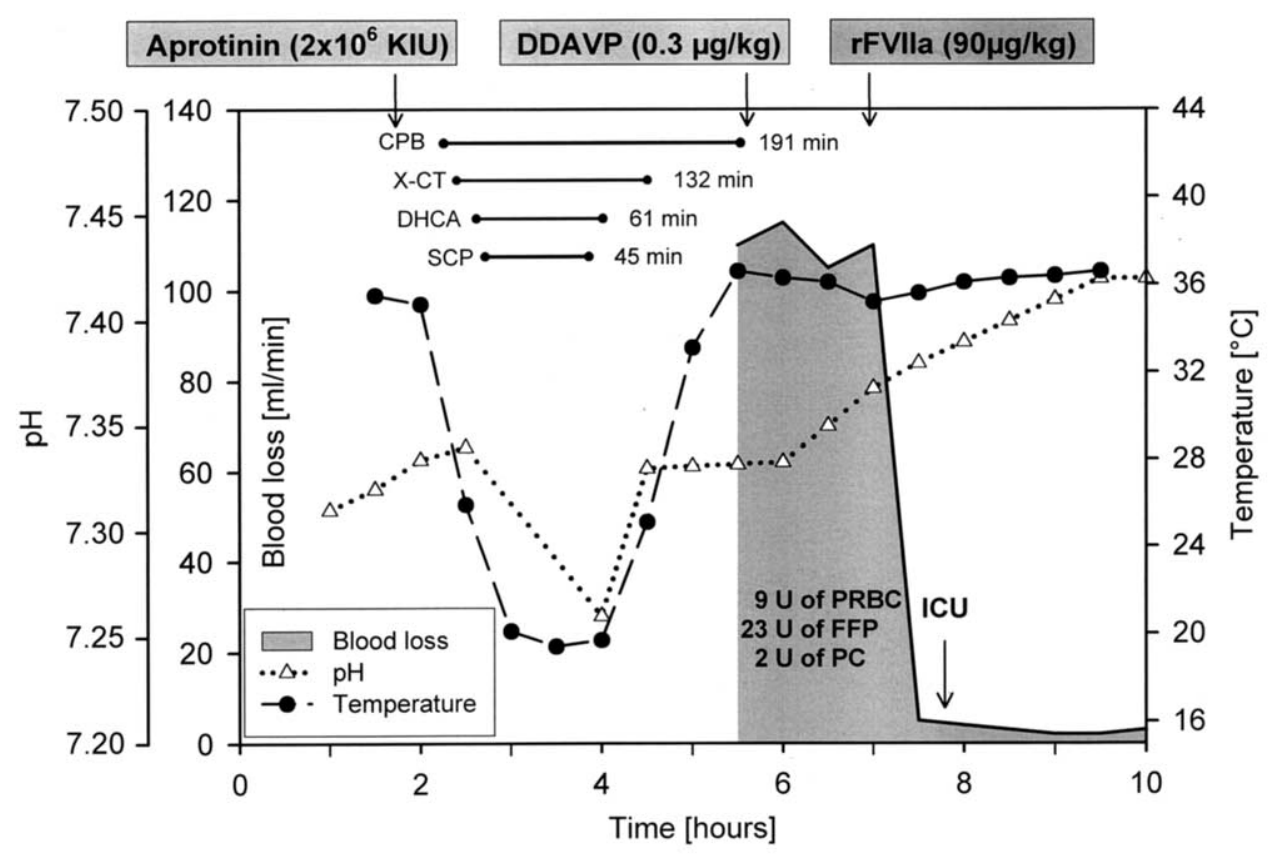

Figure 1. Graphic representation of cumulative blood loss, transfusion requirements, and the patient's temperature and $\mathrm{pH}$ during and after cardiac surgery with deep circulatory arrest. CPB, Cardiopulmonary bypass; $X$-CT, aortic crossclamp time; DHCA, deep hypothermic circulatory arrest; $S C P$, selective cerebral perfusion; rFVIIa, recombinant factor VIla; DDAVP, 1-deamino-8-D-arginine vasopressin (desmopressin); KIU, kallikrein inhibitory units; $P R B C$, packed red blood cells; FFP, fresh frozen plasma; $P C$, platelet concentrate; ICU, intensive care unit.

After flushing and deairing of the graft, antegrade perfusion was established through a preformed branch graft. During rewarming, a modified Bentall procedure ${ }^{3}$ was performed with a valvebearing composite prothesis for aortic root replacement. End-toend anastomosis of the 2 grafts completed the surgical repair. The $\mathrm{CPB}$, selective cerebral perfusion, circulatory arrest, and aortic crossclamping times were 191, 61, 45, and 132 minutes, respectively. Weaning from CPB was easily achieved with dobutamine $\left(5 \mu \mathrm{g} \cdot \mathrm{kg}^{-1} \cdot \mathrm{min}^{-1}\right)$ and norepinephrine $\left(0.05 \mu \mathrm{g} \cdot \mathrm{kg}^{-1} \cdot \mathrm{min}^{-1}\right)$ but was complicated by abundant oozing from the multiple suture sites. Even though activated clotting time returned to baseline values (126 seconds) after administration of protamine, blood loss persisted at an average rate of $110 \mathrm{~mL} / \mathrm{min}$. Desmopressin $(0.3$ $\mu \mathrm{g} / \mathrm{kg}$ ) was given to treat the aspirin-induced platelet dysfunction. Over the next 100 minutes, the patient also received $9 \mathrm{U}$ of packed red blood cells, $23 \mathrm{U}$ of fresh frozen plasma, and $2 \mathrm{U}$ of platelet concentrate, in addition to $4000 \mathrm{~mL}$ of shed mediastinal blood, without any therapeutic effect (Figure 1). Bioglue and 4 fibrincoated collagen fleeces (TachoComb; Nycomed, Linz, Austria) were used without success by the surgeon to seal the oozing suture sites. In this situation of persisting excessive bleeding without any further chance of surgical intervention, we administered $9.6 \mathrm{mg}$ $(90 \mu \mathrm{g} / \mathrm{kg}$ ) of rFVIIa. Bleeding decreased immediately in the next few minutes, and the chest could be closed. After this single dose, total blood loss from the chest drains decreased to a total of 850 $\mathrm{mL}$ over the next 24 hours. Coagulation parameters at arrival on the intensive care unit were nearly normal: international normalized ratio, 0.9; activated partial thromboplastin time, 39 seconds; and platelet count, $90 \times 10^{9} / \mathrm{L}$. Except $2 \mathrm{U}$ of fresh frozen plasma, the patient received no additional blood products, was weaned from inotropes, made a good recovery, and could be discharged from the hospital on postoperative day 18 .

\section{Discussion}

Bleeding complications after prolonged $\mathrm{CPB}$ are common, and DHCA adds further damage to the coagulation system because it involves more severe hypothermia and organ ischemia related to blood stasis. In brief, a combination of platelet dysfunction, an imbalance of fibrinolytic and antifibrinolytic systems, kinetic factors, and kinin/kallikrein perturbations all contribute to the coagulopathy induced by hypothermia. The physiological response to DHCA includes a thrombin-induced increase in activated protein $\mathrm{C}$ that prevents clotting and maintains blood fluidity through proteolysis of procoagulant factors $\mathrm{V}_{\mathrm{a}}$ and $\mathrm{VIII}_{\mathrm{a}}$ and induction of fibrinolysis by causing endothelial release of tissue plasminogen activator. $^{4}$

In the presented case, no metabolic disorders occurred, and the patient's hemodynamic situation was stable under mild inotropic support during the period of bleeding. Nevertheless, the patient's temperature decreased from $36.7^{\circ} \mathrm{C}$ at separation from $\mathrm{CPB}$ to $35.2^{\circ} \mathrm{C}$ when $\mathrm{rFVIIa}$ was given, probably because of the excessive bleeding, the open chest, and redistribution of cold blood out of less perfused tissues after prolonged DHCA. Although hypothermia by itself could be responsible for coagulation disorders, rFVIIa should be effective in enhancing hemostasis in hypothermic pa- 
tients. ${ }^{5}$ According to Meng and colleagues, ${ }^{5}$ rFVIIa activity was not reduced at $33^{\circ} \mathrm{C}$ compared with $37^{\circ} \mathrm{C}$. However, the activity of rFVIIa is considerably affected by $\mathrm{pH}$ (by $>90 \%$ at 7.0 compared with 7.4), and its efficacy may be reduced in acidotic patients.

Although rFVIIa was originally developed and licensed only for treatment of bleeding in hemophilic patients with inhibitors, it has been documented to control refractory hemorrhage after various types of surgery. Recombinant FVIIa acts by activating formation of the prothrombinase complex and has a local action only at sites of vascular injury where tissue factor and phospholipids are exposed. Furthermore, rFVIIa can bind activated platelets. Bound to the platelet surface, rFVIIa activates factor $\mathrm{X}$ and enhances the amount of thrombin generated at the platelet surface. This tissue factor-independent mechanism may explain the effectiveness of rFVIIa in the treatment of bleeding episodes in patients with aspirin-induced platelet function disorders.

In conclusion, this case suggest that rFVIIa could be applied effectively to control refractory bleeding in hypothermic patients with aspirin-induced platelet dysfunction after cardiac surgery in DHCA, but the clinician must consider the level of acidosis present before administration of rFVIIa. However, the drug is extremely expensive, and on the basis of its mechanism of action, fatal thrombosis is a potential risk. ${ }^{6}$ Therefore, rFVIIa should be applied very judiciously and only in cases of life-threatening hemorrhage without a surgical source in which all traditional means of treatment have been exhausted.

\section{References}

1. Green JA, Spiess BD. Current status of antifibrinolytics in cardiopulmonary bypass and elective deep hypothermic circulatory arrest. Anesthesiol Clin North Am. 2003;21:527-51.

2. Stratmann G, Russell IA, Merrick SH. Use of recombinant factor VIIa as a rescue treatment for intractable bleeding following repeat aortic arch repair. Ann Thorac Surg. 2003;76:2094-7.

3. Kouchoukos NT, Marshall WG Jr, Wedige-Stecher TA. Eleven-year experience with composite graft replacement of the ascending aorta and aortic valve. J Thorac Cardiovasc Surg. 1986;92:691-705.

4. Mora Mangano CT, Neville MJ, Hsu PH, Mignea I, King J, Miller DC. Aprotinin, blood loss, and renal dysfunction in deep hypothermic circulatory arrest. Circulation. 2001;104(suppl 1):I276-81.

5. Meng ZH, Wolberg AS, Monroe DM III, Hoffman M. The effect of temperature and $\mathrm{pH}$ on the activity of factor VIIa: implications for the efficacy of high-dose factor VIIa in hypothermic and acidotic patients. J Trauma. 2003;55:886-91.

6. Bui JD, Despotis GD, Trulock EP, Patterson GA, Goodnough LT. Fatal thrombosis after administration of activated prothrombin complex concentrates in a patient supported by extracorporeal membrane oxygenation who had received activated recombinant factor VII. $J$ Thorac Cardiovasc Surg. 2002;124:852-4. 